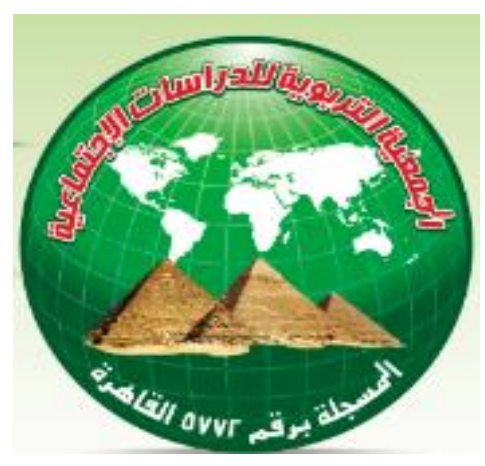

\title{
" مظاهر العنف وصوره "
}

مقالة

إع

المستشار أ. د/ عبد الرحمن الأحمد

عميد كلية التربية بجامعة الكويت سابقا

ISSN : 2535- 2032 print )

ISSN : 2735-3184 online )

العدد عسا ديسمبر ابr -rم - الجزء الأول

مقر المجلة: كلية التربية - جامعة عين شمس - روكسي ـ مصر الجديدة ـ القاهرة

web site. https://pjas.journals.ekb.eg/.

E. e.a.for.social.studies@gmail.com

T. $01002722265 \backslash 01061603061$ 


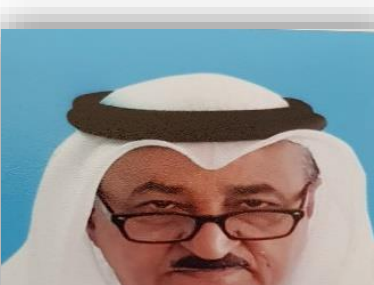

\section{مظاهر العنف وصوره}

بقلم: المستشار أ. د. عبد الرحمن الأحمد

عميد كلية التربية بجامعة الكويت سابقا

المستخلص

تتاولت هذه المقالة مظاهر العنف وصوره من حيث أنواعه وأثكاله

يتخذ العنف اشكالا متعددة سواء كان في المدرسة، ام في الجامعة، أم في الحياة العامة، ام غيرها. ويأخذ العنف لدى الثباب، أحد الأشكال الأتية:

1. العنف البسيط Simple Violence : والذي يكون من قبيل حركات التمرد الطلابي. r. العنف المحسوب Calculated Violence: والذي يكون من قبيل تحول حركات التمرد الطلابية إلى أعمال الثغب والسطو والتخريب لخضوعها لقيادات تستغل هذه الحركات لمصالحها الثخصية. r. العنف التحريضى Formented Violence : وهو من قبيل التحريض على عمليات العنف التي يقوم بها البعض مستغلين مشاعر الإحباط والعجز في هذه المجتمات. ع. العنف الغائب او الأداتى Instrumental Violence : وهو من قبيل العنف الذي يشترك فيه أفراد المجتمع دون علمهم. هـ العنف الدفاعي او الوقائى Preventive Violence: وهو من قبيل العنف، الذي نقوم به بعض مؤسسات المجتمع لمنع وقوع العنف او التهديد بالعنف، حيث ثقوم هذه المؤسسات كالثرطة بإجهاض بعض أعمال الثغب قبل أن تبدأ، وأحيانا ما ينحرف هذا النوع من العنف، وهذا العنف الدفاعي قد يتحول إلى الإفراط في استخدام القوة والتدمير بما يخرج به عن الأهداف المشروعة له، وقد أورد مجـــــلة الجمعية التبوية للمراســــات الاجتماعية - مجلة علمية محكة تصدر بصفة دورية 
الباحثون انماطا عديدة للعنف في تصنيفاتهم له، إذ استخدم بعضهم معياراً مختلفا عن المعيار الذي

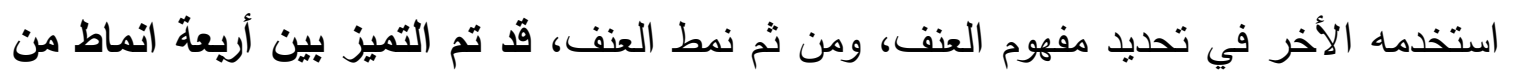

(العنف:

ا ـ العنف اللاعقلاني: وهو من العنف غبر المسؤول والذي يفتقد أي أهداف موضوعية يثور ضدها r. العنف المنشأ: الذي تلعب وسائل الاتصال دورا بارزا في إحداثه.

r. العنف الانفعالي وهو نوع من الانفجار العاطفي الذي يعبر عن مؤثرات ومشاعر متراكمة داخل الفرد. ع. العنف العقلاني: وهو أكثر أنماط العنف نضجاً وفعالية واثراً، وهو ما بمثل الجنايات المخططة والمعدة إعدادا يوظف فيها التقنية والعلم والخبرة.

هـ العنف المادي والعنف المعنوي: وهو العنف البدني او العنف الجسدي الذي يمارس في أثنكال منل الضرب والتشويه وإلقاء الأثياء على الآخرين وخطف الأثخاص والسرقة بالإكراه والاغتصاب الجنسي وتقييد حركة الأشخاص والضرب بأداة حادة، والخنق، والدفع، والعض والمسك بعنف وشد الشعر ، وهو نمط سلوكي بين الأفراد وضد الممتلكات العامة، ويتمنل بالتكسير والتخريب والتدمير والإضرار بمنشآت الجامعة ومرافقها والملصقات الجدارية والكتابة على المقاعد والجدران وغيرها.

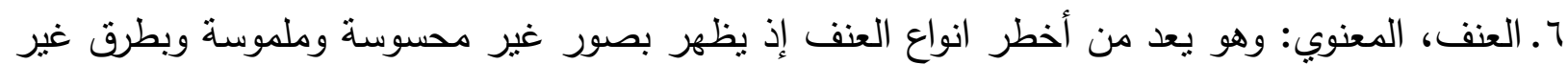
مباثرة تعمل على تقويض كرامة الفرد وإضاعة ثقته بنفسه، ويظهر من خلا النقد المتكرر، والتهكم والسخرية والإهانة والبذاءة واللغة المهينة، والاستعمال الدائم للتهديد والوعيد وله آثار مدمرة على الصحة النفسية للطالب الجامعي وللفرد بشكل عام ويتجسد بمظهرين هما: العنف اللفظى والتهديد، حيث يمارس من خلال الضغوط النفسية على الإنسان، وذلك بإخضاعه لمؤثرات ذهنية وعاطفية وإيلام نفسي وحرمان عاطفى بصورة تفقد الإنسان توازنه. ويعتبر العنف اللفظي: من اثد اثكال العنف المعنوي خطرا على سوية الحياة، لأنه يؤثز على الصحة النفسية للأفراد، وبخاصة ان الألفاظ المستخدمة تسيء إلى شخصية الفرد ومفهومه عن ذاته، حيث يتمنل العنف اللفظي في الثتم والسباب والقذف والتحريض وشهادة الزور والاستهزاء بالغير ، واستخدام الألفاظ النائية، و عبارات التهديد وعبارات تحط من الكرامة الإنسانية ونقصد بها الإهانة، كما يطلق عليه العنف النفسي، إذ يتضمن التحقير والاستهزاء والتسلط والاستبداد وإلغاء الثخصية و إلحاق الأذى بالنفس، إلا أن العنف اللفظي لا يعاقب عليه القانون، لان من الصعب قياسه وتحديده وإثباته. 
V. العنف الفردي والعنف الجماعي: لكن الأعم والأكثر انتشارا بين العلماء والباحثين هو التصنيف الذي يرى أن العنف الفردي هو قيام فرد بأفعال ظاهرة تعبر عن العدوان تجاه الآخرين، ويتمنل في اعتتاق

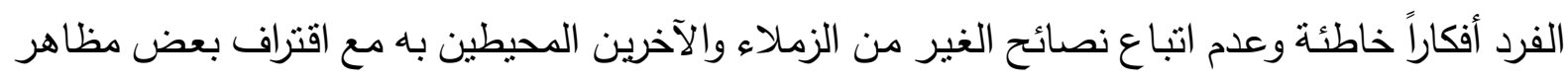
العدوان البدني واللفظي. أما العنف الجماعي فهو قيام جماعة من الأفراد بأفعال عدوانية ظاهرة (كايذاء البدن والتخريب والإيذاء اللفظي) تجاه فرد أو جماعة، ويكون الدافع أو مجموعة الدوافع التي تكمن خلفه لا يمكن نسبتها إلى شخص معين ومحدد من أفراد الجماعة، بل تستتد إلى دافع ذاتي يقوم فيه الأفراد بالإيذاء البدني أو التذمير والتخريب والحرق دون أن يكون الفرد صاحب مصلحة مباشرة في ثلك الأفعال، بل هي مصلحة الجماعة ككل دون تعب شخصي فعلي.

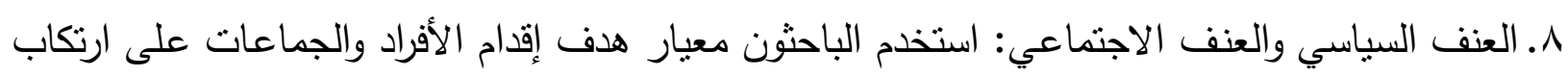
جريمتهم لتمييز العنف السياسي والعنف الاجتماعي، فإذا كان العنف موجهاً إلى النظام وموارد الدولةذلك عنفا سياسيا، وذلك تمبيزا لهذا النوع من العنف عن العنف الذى يحدث بين الأفراد في المجتمع، نتيجة العلاقات الاجتماعية والاقتصادية إلخ بينهم. وهنا فقد عرف العنف السياسي على أنه اللجوء إلى عنى

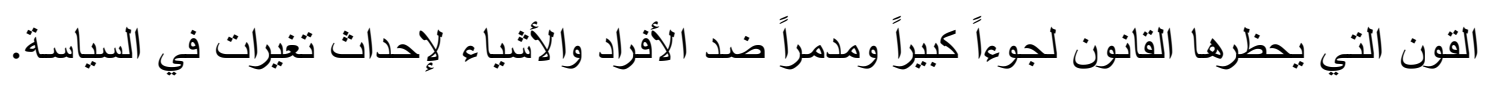

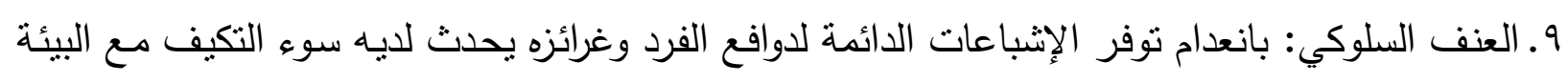

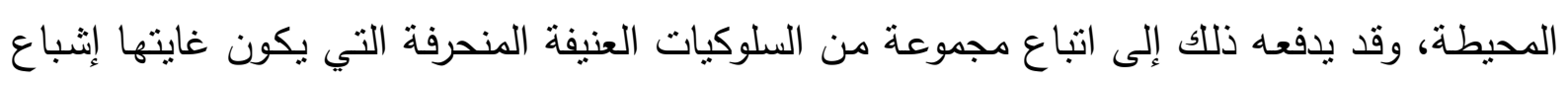
حاجاته، وقد يتسم السلوك المنحرف عند بعض الأفراد بعدم الانضباط والعنف والقسوة أو اللامبالاة الاجتماعية وكلها تؤدي إلى سلبية في عملية التطبيع الاجتماعي. فالإفراط في التتشئة يؤدي إلى التبعية والتراخي يؤدي إلى العدوانية وعنف السلوك، وللعنف السلوكي مظاهر تتحدد في العنف المحرم، إذ يتم هذا العنف في صورة عدوان من الفرد على غيره وهذا محرم قانوناً وشرعاً ومخالف للحياة الاجتماعية المستقرة. • 1. العنف الإلزامي: هو نوع من العنف القائم على النفس ضد اعتداء الآخرين سواء أكان العدوان من الآخرين في صورة فردية أم جماعية وأيضا العنف المباح: هو سلوك مباح من الشرع حيث يؤمر الإنسان بمعاملة الآخرين بذلك الفعل.

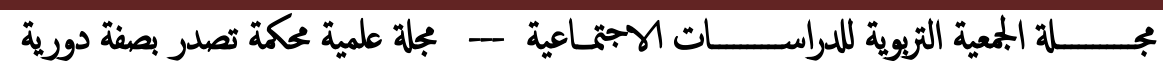


11. العنف الجنسي: وقد يقع داخل نطاق الأسرة أو خارجها، وفي كلتا الحالتين يحاط بالتكتم الثديد، والحيلولة دون وصول الحالات إلى القضاء والثرطة، لأن من شأن ذلك الإساءة إلى سمعة الأسرة،

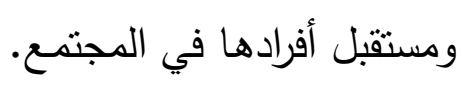

r ا. العنف الرمزي: هو عنف هادئ لا مرئي ولا محسوس حتى بالنسبة لضحاياه، ويتمثل في اشتراك الضحية وجلادها في التصورات والمسلمات نفسها عن العالم، ويتجلى هذا العنف في ممارسات قيمية بلية ووجدانية وأخلاقية وثقافية وأحياناً دينية تعتمد الرموز كأدوات في السيطرة والهيمنة مثل: اللغة، والصورة، والإثـارات والدلالات والمعاني، وكثثر ما يتجلى هذا العنف في ظل ممارسة رمزية أخلاقية ضد ضدائه ضداياه، فالعنف الرمزي مقارنة بأب شكل آخر من أشكال العنف يكون غامضا مستترا خفيا ناعما، ولكن نتائجه

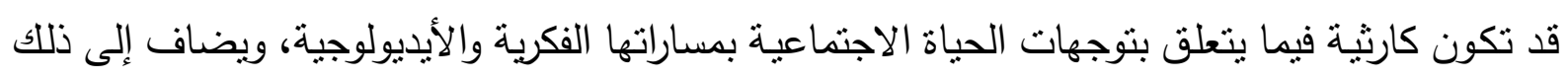

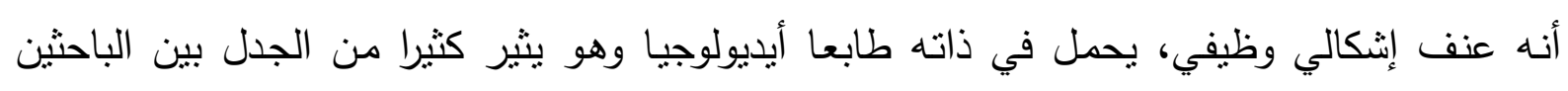

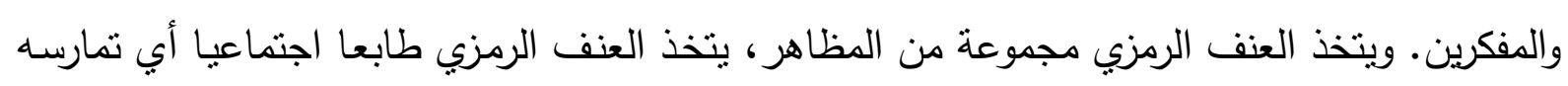
مجموعة من أفراد المجتمع مهما كانت الصورة المطبقة فهو بهذا ينأى عن الإرهاصات النفسية

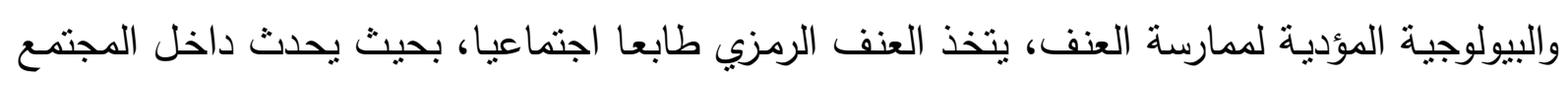

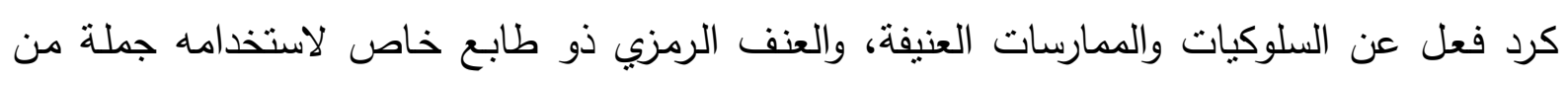
الرموز والإثارات والدلالات، وهذا الترميز قد يكون (مشاكل اجتماعية، وانحراف، وتعبير لفظي أو كتابي أو خطي)، ويتخذ العنف الرمزي طابع الصور مهما كانت الصور سواء كانت من إنتاج تللك الثريحة

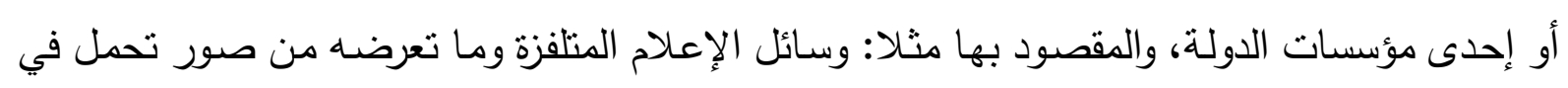
دلالتها عنفا رمزيا حيث إن لهذه الصور العنيفة الأثر العميق على انفعالات وأحاسيس الثباب.

ومن خلال ما سبق بمكن القول إن من خصائص العنف الرمزي، ما يلي: العنف الرمزي ذو قوة وله تأثير

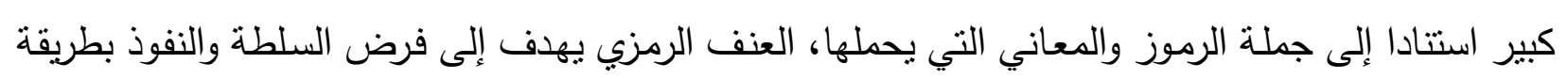
تعسفية واستبدادية

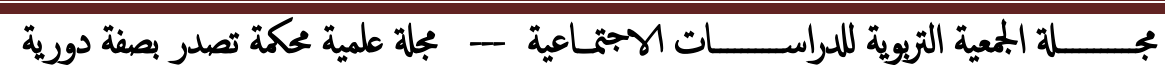

